\title{
Philosophiques
}

\section{Livres reçus (printemps 2006)}

Volume 33, numéro 1, printemps 2006

Philosophie et psychopathologie

URI : https://id.erudit.org/iderudit/012968ar

DOI : https://doi.org/10.7202/012968ar

Aller au sommaire du numéro

Éditeur(s)

Société de philosophie du Québec

ISSN

0316-2923 (imprimé)

1492-1391 (numérique)

Découvrir la revue

Citer ce document

(2006). Livres reçus (printemps 2006). Philosophiques, 33(1), 327-328.

https://doi.org/10.7202/012968ar d'utilisation que vous pouvez consulter en ligne.

https://apropos.erudit.org/fr/usagers/politique-dutilisation/ 


\section{Livres reçus (printemps 2006)}

Arendt, Hannah, Journal de pensée 1950-1973, tomes 1 et 2, Paris, Le Seuil, 2005, $1969 \mathrm{p}$.

Beaulieu, Alain (dir.), Gilles Deleuze, héritage philosophique, Paris, Presses Universitaires de France (coll. "Débats philosophiques »), 174 p.

Berlioz, Dominique et Nef, Frédéric (dir. publ.), Leibniz et les puissances du langage, Paris, Vrin (Coll. « Histoire de la philosophie »), 2005, 396 p.

Braz, Adelino, Droit et éthique chez Kant : l'idée d'une destination communautaire de l'existence, Paris, Publications de la Sorbonne, 2005, 354 p.

Bruun, Otto et Corti, Lorenzo (dir. publ.), Les catégories et leur histoire, Paris, Vrin (coll. « Histoire de la philosophie »), 2005, 396 p.

Colucci, Mario et Di Vittorio, Pierangelo, Franco Basaglia. Portrait d'un psychiatre

intempestif, trad. de l'italien par P. Faugeras, Ramonville Saint-Agne, Editions érès (coll. «Des travaux et des jours »), 2005, 230 p.

Courtine, Jean-François, Inventio analogiae. Métaphysique et ontothéologie, Paris, Vrin (coll. "Problèmes et controverses »), 2005, 377 p.

Drapeau, Filipe et Ludwig, Pascal, Kripke. Référence et modalités, Paris, Presses Universitaires de France (coll. «Philosophies »), 155 p.

Duhamel, André et Jutras, France (dir.), Enseigner et éduquer à la citoyenneté, Québec, Les Presses de l’Université Laval (coll. " La vie dans la classe »), 2005, $316 \mathrm{p}$.

Dutant, Julien et Engel, Pascal, Philosophie de la connaissance. Croyance, connaissance, justification, Paris, Vrin (coll. «Textes clés »), 2004, 448 p.

Gadamer, H. G., L'herméneutique en perspective, $1^{\mathrm{re}}$ et $2^{\mathrm{e}}$ parties, trad., présentation et notes par Jean Grondin, Paris, Vrin (coll. « Textes philosophiques »), 2005, $285 \mathrm{p}$.

Gnassounou, Bruno et Kistler, Max (dir.), Causes, pouvoirs, dispositions en philosophie. Le retour des vertus dormitives, Paris, Presses Universitaires de France, 2005, 183 p.

Guillebaud, Jean-Claude, La force de conviction. À quoi pouvons-nous croire?, Paris, Éditions du Seuil, 2005, 390 p.

Klibansky, Raymond, Idées sans frontières. Histoire et structures de l'Institut international de philosophie, Paris, Les Belles Lettres, 2005, 254 p.

Michel, Johann (dir.), Mémoires et histoires. Des identités personnelles aux politiques de reconnaissance, Rennes, Presses Universitaires de Rennes, 286 p.

Royle, Peter, L'homme et le néant chez Jean-Paul Sartre, Québec, Presses de l'Université Laval (coll. "Zêtêsis"), 2005, 132 p.

Tavaglione, Nicolas, Le dilemme du soldat. Guerre juste et probibition du meurtre, Genève, Editions Labor et Fides (coll. "Le champ éthique »), 2005, 166 p. 


\section{Philosophiques / Printemps 2006}

Outre les ouvrages qui apparaissent dans cette liste, la rédaction de Philosophiques peut obtenir, pour fin de compte rendu ou d'étude critique, la plupart des livres parus récemment.

Les personnes désireuses de faire un compte rendu ou une étude critique sont priées de s'adresser à :

\section{Jimmy Plourde}

Département de philosophie

Université du Québec à Montréal

C.P. 8888 , Succ. centre-ville

Montréal, H3C 3P8

Courriel : plourde.jimmy@uqam.ca 